\title{
Estimation of deformation and stiffness of fractures close to tunnels using data from single-hole hydraulic testing and grouting
}

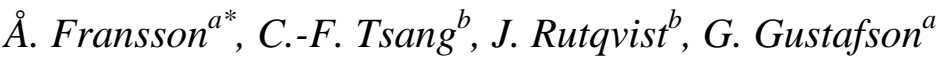 \\ ${ }^{a}$ Chalmers University of Technology, Göteborg, Sweden \\ *Corresponding author: E-mail: asa.fransson@chalmers.se, \\ Tel: +46 31772 2057, Fax: +46 317722107 \\ ${ }^{b}$ Lawrence Berkeley National Laboratory, Berkeley, California, USA
}

\begin{abstract}
Sealing of tunnels in fractured rocks is commonly performed by pre- or postexcavation grouting. The grouting boreholes are frequently drilled close to the tunnel wall, an area where rock stresses can be low and fractures can more easily open up during grout pressurization. In this paper we suggest that data from hydraulic testing and grouting can be used to identify grout-induced fracture opening, to estimate fracture stiffness of such fractures, and to evaluate its impact on the grout performance. A conceptual model and a method are presented for estimating fracture stiffness. The method is demonstrated using grouting data from four pre-excavation grouting boreholes at a shallow tunnel $(50 \mathrm{~m})$ in Nygård, Sweden, and two post-excavation grouting boreholes at a deep tunnel $(450 \mathrm{~m})$ in Äspö HRL, Sweden. The estimated stiffness of intersecting fractures for the boreholes at the shallow Nygård tunnel are low $(2-5 \mathrm{GPa} / \mathrm{m})$ and in agreement with literature data from field experiments at other fractured rock sites. Higher stiffness was obtained for the deeper tunnel boreholes at Äspö which is reasonable considering that generally higher rock stresses are expected at greater depths. Our method of identifying and evaluating the properties and impact of deforming fractures might be most applicable when grouting takes place in boreholes adjacent to the tunnel wall, where local stresses might be low and where deforming (opening) fractures may take most of the grout.
\end{abstract}

Keywords: Hydromechanical coupling, Fractured rock, Fracture normal stiffness, Stress, Hydraulic testing, Grouting

\section{Introduction}

When constructing tunnels below the groundwater level, sealing of water-conducting features is necessary to decrease the water inflow and limit the influence on the groundwater level. Lowering of the groundwater level may result in settlements and damage to buildings, particularly in areas were the soil-cover consists of clay. Sealing of tunnels is commonly performed by pre- or post-excavation grouting. In the case of pre-excavation grouting, boreholes are drilled in the tunnel front to intersect fractures to be sealed (Fig. 1a), whereas in the case of post-excavation grouting the boreholes are drilled following excavation into the walls of the tunnel (Fig. 1b). Consequently, all boreholes are found close to the tunnel wall, an area where rock stresses can be low and both rock stresses and groundwater pressure change within small distances. Considering this and the relationship between normal stress, $\sigma_{n}$, fluid pressure, $p$, and effective normal stress, $\sigma_{n}^{\prime}$ : 


$$
\sigma_{n}^{\prime}=\sigma_{n}-p
$$

the grouting pressure (fluid pressure) used when grouting can result in deformation due to hydromechanical coupling.

Indications of hydromechanical effects during grouting have been identified e.g. at Botniabanan in Sweden [1], where a change in grouting pressure resulted in a larger than expected increase in grout flow. During a grouting experiment at Äspö Hard Rock Laboratory (Äspö HRL) at $450 \mathrm{~m}$ depth fracture deformation was indicated by the sound of the rock when closing the packer of a borehole. Evans et al. [2] comment that for fractures that are verging on shear failure at the prevailing stress conditions, shear displacement can occur for a small pressure increase. The importance of the in-situ stress is also discussed by Beitnes in a study of the post-excavation grouting at Romeriksporten, Norway [3]. According to the author, a low stress in any direction increases the difficulty to obtain a good grouting result. Some consider high pressure grouting helpful and suggest this approach to achieve low tunnel inflows, e.g. [4]. However, there is a risk that grout penetrates the large aperture fractures which may open up and close parallel fractures effectively reducing grout penetration into smaller fractures. Thus, high pressure grouting may not necessarily be the solution for a general sealing of small aperture fractures. Guglielmi et al. [5] describe investigations of a superficial carbonate rock $(30 \mathrm{~m} \times 30 \mathrm{~m} \times 15 \mathrm{~m})$ that is an unconfined aquifer drained by a natural spring. Modeling performed shows that in case of parallel fractures, opening of a tested fracture induces a closing (poroelastic) of the surrounding parallel fractures. In addition, analysis related to the same site [6] considers faults intersected by bedding-planes where a high inelastic deformation magnitude at bedding-planes resulted from sliding induced by normal closing of the tested faults. In this case, damage related to the deformation explains the bedding-plane permeability increase. In addition, as commented by the authors [5], reducing the effective normal stress leads to a normal opening and reduced shear strength and during fracture shear movements aperture can change due to dilation. Deformation of fractures is likely to increase the amount of grout flowing into the tunnel (particularly for post-excavation grouting) and if not sealed, opening of the grouted and/or adjacent fractures could result in a decreased tightness of the tunnel.

Field methods for estimate of deformation and stiffness of fractures are discussed in e.g. $[5,7,8,9,10]$. In [5] a method referred to as the High-Pulse Poroelasticity Protocol (HPPP) is introduced that uses a probe with fiber-optic sensors that allows highfrequency measurements. In [7] another type of mechanical borehole device is used to evaluate fracture stiffness and storativity. In [8] an approach is presented in which a fracture was pressurized at five different pressure steps and the transmissivity distribution within the fracture was evaluated from hydraulic tests in a number of boreholes for the different pressure steps. Further, in [9] two-pressure injection tests and multiple-pressure injection tests were performed and analyses were made using coupled hydromechanical finite element simulations (ROCMAS). In [10] an effort to characterize normal stiffness and hydraulic conductivity of a major shear zone in granite at Whiteshell site in Canada is described.

Gustafson and Stille [11], on the other hand, suggested that grouting data can be used to estimate flow dimension and here we propose that flow dimension and deformation 
are closely linked under certain conditions. An open fracture with few points of contact and no fracture filling (a higher flow dimension) is more likely to deform compared to a fracture with a large amount of contact points (a lower flow dimension), and therefore it is important to identify these features. The present paper takes this approach with the objective of developing a method by which data from hydraulic testing and grouting can be used to identify deforming fractures, estimate fracture stiffness and indicate low effective stress close to a tunnel. This can then serve as a tool to better adapt the grouting design and improve its performance.

In this paper, a conceptual model and a method are presented for estimating fracture normal stiffness. The local stresses may be unknown but we recognize that a low stiffness generally indicate a low effective stress. The method is demonstrated using grouting data from four pre-excavation grouting boreholes at a shallow tunnel $(50 \mathrm{~m})$ in Nygård, Sweden, and two post-excavation grouting boreholes at a deep tunnel (450 m) in Äspö HRL, Sweden. For the shallow Nygård tunnel the stresses are expected to be low and some boreholes with a flow dimension between two (2D) and three (3D) where identified and investigated. A 3D-flow could be a direct indication of deformation. As a comparison, the two boreholes from the deep Äspö HRL are investigated, here higher stresses are expected but deformation can occur also at this depth. The data used here are often available from normal grouting applications and since grouting is made along the tunnel this would provide valuable information that could be used for modification of grouting design and possibly also for reinforcement design.

\section{Method}

\section{Flow dimension}

The flow dimension is considered important. For a two dimensional flow, few points of contact within the fracture and a low fracture stiffness are expected. During grouting, grouting pressure, $p_{g}$, grouted volume or grout take, $V$, flow of grout, $Q$, and time, $t$, are documented. These $p V t$-data can be used to identify flow dimension using the expression by Gustafson and Stille [11]:

$$
\frac{d \log V}{d \log t}=\frac{d \ln V}{d \ln t}=\frac{d V}{V} \cdot \frac{t}{d t}=\frac{d V}{d t} \cdot \frac{t}{V}=\frac{Q \cdot t}{V}
$$

According to the authors [11] a slope of $d \log V / d \log t \approx 0.8$ indicates a radial (2D) grout spread and a slope of $d \log V / d \log t \approx 0.45$ means a $1 \mathrm{D}$ flow system. The general idea is that fractures with a flow dimension smaller than two is expected to be less influenced by hydromechanical coupling. If the flow dimension is larger than two, this could be a direct sign of fracture deformation.

Conceptual model: Estimate of fracture stiffness

The fracture normal deformation is expressed:

$$
\Delta u_{n}=\frac{\Delta \sigma_{n}^{\prime}}{k_{n}}=\frac{\Delta \sigma_{n}-\Delta p}{k_{n}}
$$


In this expressions, $\Delta \sigma_{n}^{\prime}$ is change in the effective normal stress, $\Delta \sigma_{n}$, is the change in total normal stress, $\Delta p$, is the fluid pressure change and $k_{n}$ is the fracture normal stiffness. Although the normal deformation is generally non-linear when normal stress is applied, it may be approximated to be a linear function of effective stress over an incremental displacement $\Delta u_{n}$. The rate of deformation is greatest at low values of normal stress. This has been described by e.g. Rutqvist and Stephansson [12].

When a fracture is filled with grout under pressure, a deformation may occur, see Fig. 2. A change in pressure results in a fracture volume change, $\Delta V$, and the hypothesis is that this can be used to estimate fracture stiffness. At a certain time, $t$, the integral of the fluid pressure change, referred to as $\AA$, see [13], has resulted in a deformation giving a larger fracture aperture. The mean (arithmetic) aperture of a deformed fracture, $b_{\text {adef }}$, is therefore assumed to consist of the initial aperture, $b_{0 a}$ that will be estimated using hydraulic tests, and a deformation due to grouting, $\Delta b_{a}$ :

$$
b_{\text {adef }}=\Delta b_{a}+b_{0 a}
$$

The principal idea is that the aperture, $b_{a d e f}$ resulting from grout-induced fracture opening can be estimated based on a penetration length, $I$, and a grout take measured in the field, $V_{\text {field, } t}$ at a certain time, $t$ :

$V_{\text {field }, t}=\pi \cdot b_{\text {adef }} \cdot I^{2}-\pi \cdot b_{\text {adef }} \cdot r_{w}^{2}$

The radius of the borehole is $r_{w}$.

To estimate fracture normal stiffness [13]:

$$
k_{n}=\frac{\AA}{\Delta V}
$$

we need a fracture volume change:

$$
\Delta V=\pi \cdot \Delta b_{a} \cdot\left(I^{2}-r_{w}^{2}\right)
$$

and the areal integral of the fluid pressure change, $\AA$.

In the above formulation, two points are to be noted. First, Eq. (3) the change in effective normal stress $[\mathrm{Pa}]$ is divided by the fracture normal deformation $[\mathrm{m}]$ to obtain a fracture normal stiffness $[\mathrm{Pa} / \mathrm{m}]$. Second, in Eq. (6), the areal integral of the fluid pressure change, $\AA\left[\mathrm{Pa} \cdot \mathrm{m}^{2}\right.$ or $\left.\mathrm{N}\right]$ is divided by the fracture volume change $\left[\mathrm{m}^{3}\right]$ to obtain the fracture normal stiffness $[\mathrm{Pa} / \mathrm{m}]$.

To estimate the areal integral of fluid pressure change, $\AA$, radial (2D) flow is assumed and for simplification, the pressure profile is described by a cone:

$$
\AA=\Delta p \cdot \pi \cdot\left(I^{2}-\frac{2}{3} I^{2}-r_{w}^{2}+\frac{2}{3} \frac{r_{w}^{3}}{I}\right)
$$


For a Newtonian fluid, the actual pressure profile would result in a lower value of the parameter $\AA$, compared to Eq. (8). This can be corrected by a factor $\mathrm{f}\left(\mathrm{r}_{\mathrm{w}}, I\right)$, which is less than 1 , but is close to 1 if $I$ is not too many times larger than $r_{w}$. However, other factors also come in. For example, if the pressure is influenced by a closed boundary and the overall pressure in the fracture increases; this would result in a higher value of the $\AA$-parameter. The principal sketch in Fig. 2 suggests that the pressure at the grouting front is equal to the initial water pressure, $p_{w}$. If an increase in water pressure would be the consequence of grouting, this would result in a higher water pressure within the fracture and the areal integral of the fluid pressure change, $\AA$, would increase. Another consequence in this case could be a shorter penetration of grout due to a smaller grouting over pressure ( $p_{g}$ is the same but $p_{w}$ increases, $\Delta p=p_{g}-p_{w}$ ). Assuming that the grout take measured in the field, $V_{\text {field,t }}$ is the same, a shorter penetration of grout would result in a larger estimated value of the deformed aperture, $b_{\text {adef }}$ (Eq. 5) and a larger fracture volume change, $\Delta V$. Since both $A$ and $\Delta V$ increase, the influence on fracture normal stiffness is not necessarily very large. Until this is further investigated a cone simplification with $f=1$ is used.

Equations above can be used to estimate fracture normal stiffness. First we estimate an initial hydraulic aperture, $b_{0 h y d}$, using the cubic law [14]:

$T=\frac{\rho_{w} g b_{0 h y d}^{3}}{12 \mu_{w}} \approx \frac{Q}{d h}$

where flow, $Q$, and difference in hydraulic head, $d h$, are obtained from hydraulic testing of grouting boreholes before grouting. A field experiment presented in [15] shows that the specific capacity evaluated from hydraulic tests gives a picture of the local hydraulic properties of a fracture. Further, the median specific capacity was found to be a good description of the transmissivity, $T$, of the fracture. This means that the variation in aperture is in some way taken into account using data from individual boreholes. Note that here we assume the fracture aperture, while changing with time and condition, is approximately constant spatially. This is based on a joint field experiment and numerical modeling study by Wessling et al. [16] who show that in a coupled hydromechancial process the fracture aperture tends to open or close uniformly.

The next step is to estimate penetration length, $I$, and hydraulic aperture of the deformed fracture, $b_{\text {hyd.def }}$, using the grout take from grouting field data as input, see Eq. (5). According to Gutjahr et al. [17], the effective conductivity of a log-normal distributed hydraulic conductivity may be described using the geometric mean resulting in $b_{g}$ equal to $b_{\text {hyd }}$, see Eq. (10). When grouting, the hydraulic aperture, $b_{\text {hyd }}$, also described as the median aperture or the geometric mean, $b_{g}$, is assumed to govern the penetration length, $I$, whereas the arithmetic mean, $b_{a}$, takes into account the volume of the fracture. In the work presented by Hakami [18], the mean aperture, $b_{a}$, was found to be 1.1-1.7 times the median aperture, $b_{g}$ or $b_{\text {hyd }}$. According to the author [18], this ratio is of the same order as those reported from a number of other studies with a mean aperture between 0.1 and $0.5 \mathrm{~mm}$.

Based on the above, the relation between the arithmetic and geometric mean (hydraulic aperture) is described: 
$b_{a}=a \cdot b_{g}=a \cdot b_{\text {hyd }}$

Further, the geometric mean for the deformed fracture is referred to as $b_{\text {hyd.def }}$. Eqs. (5) and (10) give:

$V_{\text {field }, t}=\pi \cdot a \cdot b_{\text {hyd.def }} \cdot I^{2}-\pi \cdot a \cdot b_{\text {hyd.def }} \cdot r_{w}^{2}$

As a simplification $a$ will be set to one, i.e. the hydraulic aperture, $b_{\text {hyd }}$, and the arithmetic aperture, $b_{a}$, is assumed to be the same. In a comparison of real mechanical aperture and the theoretical smooth wall conducting aperture [19] smooth walls or very wide aperture results in these parameters being equal. Losses due to tortuosity and surface roughness are small in these cases. Further, it is reasonable to suggest that few points or areas of contact and a large area available to flow would result in both small losses and a low normal fracture stiffness. Flow in these fractures would be very sensitive to deformation.

The penetration length, $I$, of the grouting material (silica sol) is expressed by Funehag and Gustafson, [20]:

$$
I=I_{G} \cdot I_{D}
$$

where, for silica sol,

$$
I_{G}=b \sqrt{\frac{\Delta p t_{G}}{6 \mu_{0}}}
$$

$I_{D}$ is a dimensionless penetration length, $I_{G}$ defines a length-scale for the problem, $t_{G}$ is the gel induction time and $\mu_{0}$ the viscosity. Here the aperture is $b=b_{\text {hyd.def. }}$

The penetration length for 1D flow is approximately twice the penetration length for $2 \mathrm{D}$, radial flow. Different values of $I_{D}$, Eq. (12), have to be used. For 1D flow the following equation applies [20]:

$$
I_{D-1 D}=\sqrt{t_{D}-\frac{1}{\alpha} \ln \left(\frac{e^{\alpha}+e^{\alpha \cdot t_{D}}}{e^{\alpha}+1}\right)}
$$

A dimensionless time, $t_{D}$, is included in the equation and the parameter, $\alpha$, depends upon the rheology of the silica sol. $t_{D}$ is expressed:

$$
t_{D}=\frac{t}{t_{G}}
$$

where $t_{G}$ is the gel induction time (gelling time/3). In practice the gelling time is obtained when a silica sol front in a cup does not move or bend when turning the cup $90^{\circ}$, see e.g. [21].

For 2D flow the following equation can be used [20]: 
$I_{D-2 D, n+1}=\sqrt{\frac{t_{D}-\frac{1}{\alpha} \ln \left(\frac{e^{\alpha}+e^{\alpha \cdot t_{D}}}{e^{\alpha}+1}\right)+r_{D}^{2} / 2}{\left.\ln \left(I_{D-2 D, n} / r_{D}\right)+1 / 2\right]}}$

where

$r_{D}=\frac{r_{w}}{I_{G}}$

To estimate a first value of $I_{D-2 D}$, the result from Eq. (14), $I_{D-1 D}$ for $1 \mathrm{D}$ flow, is used as initial value, $I_{D-2 D, n}$, Eq. (16).

Eqs. (11) - (17), give:

$V_{\text {field }, t}=\pi \cdot 1 \cdot b_{\text {hyd.def }} \cdot\left(b_{\text {hyd.def }} \sqrt{\frac{\Delta p \cdot t_{G}}{6 \cdot \mu_{0}}} \cdot I_{D-2 D}\right)^{2}-\pi \cdot 1 \cdot b_{\text {hyd.def }} \cdot r_{w}^{2}$

and all parameters included in Eqs. (5) - (8), except for the hydraulic aperture of the deformed fracture, $b_{\text {hyd.def, }}$ (here assumed equal to $b_{\text {adef }}$ ) and the deformation due to grouting, $\Delta b_{a}$ are known. Eq. (18) and then Eq. (4) are solved to determine these values. Finally, the fracture volume change, $\Delta V$, Eq. (7), and the areal integral of the fluid pressure change, $\AA$, Eq. (8), are used to estimate a fracture normal stiffness, $k_{n}$, Eq. (6).

\section{Case studies: Grouting boreholes from the the Nygård tunnel and Äspö HRL}

The method is demonstrated using grouting data from four grouting boreholes at a shallow tunnel $(50 \mathrm{~m})$ in Nygård (pre-excavation grouting) and two grouting boreholes at a deep tunnel $(450 \mathrm{~m}$ ) in Äspö HRL (post-excavation grouting), Sweden. Flow dimension is investigated and comments on the normal and effective stresses are given. Further, the fracture stiffness is estimated and compared to results from the literature. For the Nygård tunnel, main rock types are gneiss and amphibolite and for Äspö HRL, Äspö diorite is the dominating type of rock. Fracture orientation is not known but for the Nygård case, geological mapping of the tunnel wall following grouting indicate fractures sub-parallel $\left(<45^{\circ}\right)$ to the tunnel front. Future work would include more detailed descriptions of fracture orientation.

\section{Flow dimension}

The flow dimension was investigated to look at the hydromechanical behaviour of the fracture and to confirm that the conceptual model can be used for the boreholes (demands 2D flow). For the six grouting boreholes investigated at Nygård and Äspö, the values were higher than or close to 0.8 indicating an initial flow dimension of $2 \mathrm{D}$ to $3 \mathrm{D}$ for all boreholes. Estimates of stiffness could be made from these data since the conceptual model only demands an initial 2D flow, whereas a flow dimension higher than two is considered to be a result of fracture deformation. Borehole 5F03 has a flow dimension that goes from 2D and then decreases thus indicating a channelled flow. 


\section{Comments on the normal and effective stresses}

Eq. 1 is modified so that the fluid pressure, $p$, includes both the water pressure, $p_{w}$, and the grouting overpressure, $\Delta p,\left(\Delta p=p_{g}-p_{w}\right)$ :

$$
\sigma_{n}^{\prime}=\sigma_{n}-\left(p_{w}+\frac{\Delta p}{3}\right)
$$

Due to the assumption that the pressure profile is described by a cone, the grouting overpressure is divided by three to get the average pressure change. The normal stresses for the fractures intersecting the grouting boreholes at Nygård tunnel and Äspö HRL are not known. Assuming that the stress due to the overburden, $\sigma_{z}$, has to be larger than the fluid pressure in the fracture to avoid large deformations or jacking gives:

$$
\sigma_{z}=\rho_{r} g H \geq p_{w}+\frac{\Delta p}{3}
$$

A possible result is that the effective normal stress for the Nygård boreholes is low $\left(\sigma_{z}=\rho_{r} g H=2700 \cdot 9.81 \cdot 50 \approx 1.3 \mathrm{MPa}\right.$ and fluid pressure, $p_{w}+\Delta p / 3 \approx 0.5+(2.5-0.5) / 3 \approx$ 1.2 $\mathrm{MPa}$, see Table 2). Here, $\rho_{r}$ is the density of the rock, $g$ the gravity, $H$ the tunnel depth, $p_{w}$ the water pressure and $\Delta p$ the grouting over pressure $\left(p_{g}-p_{w}\right)$. If considering redistribution of stresses in the vicinity of the tunnel front the normal stresses can be even lower. For Äspö data, stress due to the weight of the overburden is higher and approximately $12 \mathrm{MPa}\left(\sigma_{z}=\rho_{r} g H=2700 \cdot 9.81 \cdot 450\right)$, however redistribution of stresses close to the tunnel may result in a normal stress that is close to the fluid pressure. For one of the boreholes the fluid pressure is approximately $4 \mathrm{MPa}\left(p_{w}+\Delta p / 3 \approx 2.9+(6.0-\right.$ $2.9) / 3 \approx 3.9 \mathrm{MPa}$, see Table 2 ) and for the other borehole the fluid pressure is low (estimated to $0.8 \mathrm{MPa}$ ).

\section{Estimate of fracture stiffness}

Hydraulic tests at Nygård and Äspö were performed as water pressure tests (exceeding the fluid pressure) or natural inflow measurement (opening of the borehole). Therefore the areal integral of the fluid pressure change, $\AA$, are estimated in different ways, see Fig. 3.

For a natural inflow measurement, the decrease in pressure in the vicinity of the borehole may lead to a decrease in aperture. For both water pressure tests and grouting a pressure exceeding the natural water pressure are used resulting in an increase in pressure and aperture. Here, the areal integral of the fluid pressure change, $A$, from natural inflow measurements are estimated:

$\AA \approx A \cdot\left(p_{w} / 3+\Delta p / 3\right)=A \cdot\left(p_{w} / 3+\left(p_{g}-p_{w}\right) / 3\right)=A \cdot p_{g} / 3$

where $A$ is the influenced area related to the penetration length, $I$. For water pressure tests the following expression is used:

$$
\AA \approx A \cdot\left(\Delta p_{g} / 3-\Delta p_{W P T} / 3\right)=A \cdot\left(\left(p_{g}-p_{w}\right) / 3-\left(p_{W P T}-p_{w}\right) / 3\right)=A \cdot\left(p_{g} / 3-p_{W P T} / 3\right)
$$


Table 1 and Table 2 present estimates of hydraulic aperture and fracture stiffness. The initial hydraulic apertures, $b_{0}$ (since $b_{\text {hyd }}$ is assumed to be equal to the arithmetic mean, $b_{a}$ ), are between $45 \mu \mathrm{m}$ and $135 \mu \mathrm{m}$. The gel induction time, $t_{G}$ for the silica sol was between 180 and approximately 1000 seconds for the different boreholes. During the time, $t$ (60 seconds) the grout take measured in the field, $V_{\text {field,t: } 60 s}$, was generally between 20 and 35 litres. For boreholes Fan 1 bh 18 and 5F03 the grout takes were lower and therefore expected to be less certain. The estimated fracture stiffness, $k_{n}$, for the shallow tunnel (Nygård) is between $2 \mathrm{GPa} / \mathrm{m}$ and $5 \mathrm{GPa} / \mathrm{m}$ and for the deep tunnel at Äspö HRL $35 \mathrm{GPa} / \mathrm{m}$ and approximately $600 \mathrm{GPa} / \mathrm{m}$. The increase in penetration length for the initial aperture, $b_{0}$, and the deformed aperture, $b_{\text {def }}$, is not very large. For Fan 1 bh 18 the penetration for the deformed fracture, $I_{d e f}$, is 2.6 times longer than the penetration for the initial hydraulic aperture.

\section{Discussion}

One problem during grouting is when grout flows back into the tunnel. One reason could be the hydraulic gradient around the tunnel and the water flow eroding and transporting the grout. Another reason, also influencing the above, could be deformation allowing the fracture aperture to increase and the grout to flow in a more uncontrolled way. In addition, normal deformation of one fracture could risk shearing of intersecting fractures [6]. An increased aperture of both the grouted fracture and intersecting fractures is a possible consequence. If those fractures are not sealed an increased ability of the rock surrounding the tunnel to transport water is a possible result. When deformation and grouting is considered, the fractures having the largest aperture, few points of contact and no fracture filling (with a low stiffness and a pronounced 2D flow) and a resulting large penetration of grout are therefore expected to give most problems.

When grouting, registration of pressure, grout volume and time is made and these data can be used to estimate flow dimension [11] and the hypothesis suggested for this work is that flow dimension and deformation are coupled under certain conditions. For a fracture having large amount of contact areas the flow is more likely to be one dimensional (channeled) whereas a fracture with few points of contact would be likely to have a more pronounced radial (2D) flow. For a fracture with a low stiffness deformation could be large and the flow dimension could therefore be larger than $2 \mathrm{D}$ (going towards 3D).

Considering field data, the stresses are not known in detail, but for the Nygård tunnel they are likely to be low. For all boreholes, analyses of $p V t$-data from grouting result in a flow that is approximately $2 \mathrm{D}$ or larger than $2 \mathrm{D}$. Results for the two tunnels are summarized in Table 3. The estimated stiffness of intersecting fractures for the boreholes at the shallow (50 meter) Nygård tunnel are $2-5 \mathrm{GPa} / \mathrm{m}$ and about the same as presented by authors [5], [8] and [22]. In [8] the hydromechanical behaviour of a pressurized single fracture found 11 meters beneath the tunnel floor is investigated (the tunnel is located at a depth of approximately 70 meters). In the papers [5] and [22] the behaviour of fractures in a carbonate rock (rock volume $30 \mathrm{~m} \times 30 \mathrm{~m} \times 15 \mathrm{~m}$ ) by the ground surface is examined. The largest aperture resulting in the lowest stiffness (see Table 2) is in agreement with the results presented by Alm [8], where a fracture aperture of $250 \mu \mathrm{m}$ resulted in the lowest stiffness (about $2 \mathrm{GPa} / \mathrm{m}$ ). The normal stiffness 
evaluated for tests for the carbonate rock had values between approximately 1.4 and 200 $\mathrm{GPa} / \mathrm{m}$. For these data as well, the largest aperture had the lowest stiffness. Rutqvist and co-authors $[23,24,9]$ present results from an investigated cored borehole at Äspö HRL. The smallest effective stress for the tests was $1.4 \mathrm{MPa}$ and the hydraulic stiffness varied between $30-1100 \mathrm{GPa} / \mathrm{m}$ for apertures ranging from 8 to $164 \mu \mathrm{m}$. A combination of a high stiffness and a large aperture could be due to the borehole intersecting a conductive channel within a fracture. The most pronounced three dimensional flow is found for the boreholes in Fan 5 for the Nygård tunnel. The data from these boreholes also results in the lowest stiffness.

Even though data are limited and the quality of grouting field data could be improved, suggested here is that the volume and area available to flow in a fracture, $V_{\text {flow }}$ and $A_{\text {flow }}$, could be a way of indicating the amount of contact points and a way of coupling flow dimension and stiffness, see sketch in Fig. 4. Using these parameters and not only the aperture, $b$, suggests that the aperture and also the flow channel geometry (or distance between contact points) and the area influenced by pressure (e.g. the penetration length of grout) are important for estimate of fracture normal stiffness. For a developed 2D flow, few points of contact are expected and the volume available to flow, $V_{\text {flow }}$, could be large compared to the area in contact with flow resulting in flow resistance, $A_{\text {flow }}$. This would be the case for the Nygård tunnel data. When closing the fracture (increasing stress), the number of contact points increases and the factor, $V_{\text {flow }} / A_{\text {flow }}$ along a flow path decreases. This could be the case for the Äspö borehole with a flow dimension going from 2D to 1D flow resulting in a possible combination of a high stiffness, a large amount of contact points and a 1D flow. A fracture with fracture filling could also result in a 1D flow. However, the large portion of the fracture area filled with geological material will result in high resistance to flow, small grout penetration and limited fluid pressure within the fracture. Open fractures with a 2D flow results in a lower flow resistance and a larger penetration of grout. The larger fluid pressure change is more likely to result in deformation and these fractures are therefore of greater interest when considering deformation and grouting.

\section{Concluding remarks}

This paper suggests that data from hydraulic testing and grouting can be used to identify deforming fractures, estimate fracture stiffness and indicate low effective stress close to a tunnel. A conceptual model and a method are presented for estimating fracture stiffness. The local stresses are not known but we recognize that a low stiffness generally indicates a low effective stress. The method is demonstrated using grouting data from four pre-excavation grouting boreholes at a shallow tunnel $(50 \mathrm{~m})$ in Nygård, Sweden, and two post-excavation grouting boreholes at a deep tunnel (450 m) in Äspö HRL, Sweden. For the shallow Nygård tunnel the stresses are expected to be low and some boreholes with a flow dimension between two (2D) and three (3D) where identified and investigated. A 3D flow could be a direct indication of deformation. As a comparison, two boreholes from the deep Äspö HRL are investigated, here higher stresses are expected but deformation can occur also at this depth. It is reasonable to believe that fractures may open up unevenly when pressurized so that fractures or parts of fractures that have a lower initial normal stress (e.g. within the reduced stress zone near a tunnel wall) can open up. Then the grout would flow through the part that opens 
and into the tunnel. This should be strongly affected by the fracture orientation relative to the tunnel.

The estimated stiffness of intersecting fractures for the boreholes at the shallow Nygård tunnel are low $(2-5 \mathrm{GPa} / \mathrm{m})$ and in agreement with literature data from field experiments at other fractured rock sites. Higher stiffness was obtained for the deeper tunnel boreholes at Äspö which is reasonable considering that generally higher rock stresses are expected at a greater depth. The most pronounced three dimensional flow is found for the boreholes in Fan 5 for the Nygård tunnel. The data from these boreholes also result in the lowest stiffness.

The above indicate that data from single hole hydraulic testing and grouting can be used to identify fracture deformation (3D flow) and estimate fracture stiffness.

Suggested is that a low fracture stiffness can be used to indicate low effective stress around the tunnel. Already a flow dimension larger than two seems to identify deforming fractures. For design and performance of grouting, deformation could be taken into account using e.g. lower grouting pressure and longer grouting time for boreholes with large inflow, particularly if this inflow is identified at a single location along the borehole (one fracture) and close to the tunnel wall. In addition, grouting packers could be moved further into the borehole where the rock stresses can be expected to be higher and the flow path for the grout is longer. Finally, development and use of on-line systems for estimate of flow dimension and stiffness during grouting is suggested. This kind of information could be used to adapt the pressure during grouting.

In this paper it seems we have found a way to identify deforming fractures during grouting. A next interesting step would be further verification including investigation of the location and orientation of fractures and actually measuring the fracture deformation during grouting.

\section{Acknowledgements}

The first author wishes to thank the Swedish Research Council for Environment, Agricultural Sciences and Spatial Planning (Formas) for financial support. Further, thanks go to PhD student Christian Butrón for the collaborative work when analyzing flow dimensionality for the Nygård tunnel. Funding for contributions from the Berkeley Lab authors was provided by the U.S. Dept. of Energy under Contract No. DE-AC02$05 \mathrm{CH} 11231$.

\section{References}

[1] Gothäll R, Stille H. Fracture dilation during grouting. Tunnell Underground Space Tech 2008;24:126-135.

[2] Evans K F, Cornet F H, Hashida T, Hayashi K, Ito T, Matsuki K, Wallroth T. Stress and rock mechanics issues of relevance to HDR/HWR engineered geothermal systems: review of developments during the past 15 years. Geothermics 1999;28:455-474.

[3] Beitnes A. Lessons to be learned from Romeriksporten. Tunnels Tunnelling Int 2005;37:36-38.

[4] Barton N. The theory behind high pressure grouting - Part 1. Tunnels Tunnelling Int 2004; September:28-30. 
[5] Guglielmi Y, Cappa F, Virieux J, Rutqvist J, Tsang C-F, Thoraval A. A new in-situ approach for hydromechanical characterization of mesoscale fractures: the High-Pulse Poroelasticity Protocol (HPPP). In: Proceedings of the 42nd US Rock Mechanics Symposium and 2nd U.S.-Canada Rock Mechanics Symposium, San Francisco, CA, 2008.

[6] Guglielmi Y, Cappa F, Rutqvist J, Tsang C-F, Thoraval A. Mesoscale characterization of coupled hydromechanical behavior of a fractured-porous slope in response to free water-surface movement. Int J Rock Mech Min Sci 2008;45:862-878. [7] Svenson E, Schweisinger, T, Murdoch, L C. Field evaluation of the hydromechanical behavior of flat-lying fractures during slug tests, Journal of Hydrology 2008;359:30-45.

[8] Alm P. Hydro-mechanical behaviour of a pressurized single fracture: an in-situ experiment. PhD thesis, Chalmers University of Technology, Göteborg, 1999, 102 p.. [9] Rutqvist J, Noorishad J, Tsang C-F. Determination of fracture storativity in hard rocks using high-pressure injection testing. Water Resour Res 1998;34:2551-2560. [10] Martin C D, Davison C C, Kozak E T. Rock joints (Barton \& Stephansson, eds). Characterizing normal stiffness and hydraulic conductivity of a major shear zone in granite. Balkema, Rotterdam, Netherlands, 1990.

[11] Gustafson G, Stille H. Stop criteria for cement grouting. Felsbau 2005;3:62-68. [12] Rutqvist J, Stephansson O. The role of hydromechanical coupling in fractured rock engineering. Hydrogeol J 2003;11:7-40.

[13] Fransson $\AA$, Tsang C-F, Rutqvist J, Gustafson G. A new parameter to assess hydromechanical effect in single-hole hydraulic testing and grouting. Int J Rock Mech Min Sci 2007;44:1011-1021.

[14] Snow D-T. Rock fracture spacings, openings, and porosities. J Soil Mech Foundations Div, Proceedings Am Soc Civ Eng 1968;January:73-91.

[15] Fransson $\AA$. Characterisation of a fractured rock mass for a grouting field test. Tunnell and Underground Space Tech 2001;4:331-339.

[16] Wessling S; Junker R, Rutqvist J, Silin D, Sulzbacher H, Tischner T, Tsang C-F. Pressure analysis of the hydromechanical fracture behaviour in stimulated tight sedimentary geothermal reservoirs, Geothermics 38:211-226, 2009.

[17] Gutjahr A L, Gelhar L W, Bakr A A, MacMillan J R. Stochastic analysis of spatial variability in subsurface flow 2. Evolution and application. Water Resour Res 1978;14:953-959.

[18] Hakami E. Aperture distribution of rock fractures. PhD thesis, Royal Institute of Technology, Stockholm, 1995, 22 p.

[19] Olsson R, Barton N. An improved model for hydromechanical coupling during shearing of rock joints. Int J Rock Mech Min Sci 2001; 3:317-329.

[20] Funehag J, Gustafson G. Design of grouting with silica sol in hard rock - New methods for calculation of penetration length, Part I. Tunnell Underground Space Tech 2008;23:1-8.

[21] Butron C, Gustafson G, Funehag J. Grouting in the Nygård Tunnel: Pre-grouting Design for Drip Sealing and Evaluation. Report No. 2008:2, Division of GeoEngineering, Chalmers University of Technology, Göteborg, 2008.

[22] Cappa F, Guglielmi Y, Rutqvist J, Tsang C-F, Thoraval A. Hydromechanical modeling of pulse tests that measure both fluid pressure and fracture-normal displacement at the Coaraze Laboratory site, France. Int J Rock Mech Min Sci 2006;43:1062-1082. 
[23] Rutqvist J, Noorishad J, Stephansson O, Tsang C. -F. Theoretical and field studies of coupled hydromechanical behaviour of fractured rocks - 2. Field experiment and modelling. Int. J. Rock Mech. Min. Sci. \& Geomech. Abstr. 1995;32:513-523.

[24] Rutqvist J. Determination of hydraulic normal stiffness of fractures in hard rock from hydraulic well testing. Int J Rock Mech Min Sci \& Geomech Abstr 1995;32:513523. 


\section{List of notations}

$a[-] \quad$ factor relating the arithmetic and geometric mean (hydraulic aperture)

$A\left[\mathrm{~m}^{2}\right] \quad$ grouted area related to penetration length, $I$

$b_{a}[\mathrm{~m}] \quad$ mean (arithmetic) aperture of a fracture

$b_{\text {adef }}[\mathrm{m}] \quad$ mean (arithmetic) aperture of a deformed fracture

$b_{0 a}[\mathrm{~m}] \quad$ initial (arithmetic) aperture

$\Delta b_{a} \quad$ deformation of mean (arithmetic) aperture due to grouting

$b_{g}[\mathrm{~m}] \quad$ mean (geometric) aperture of a fracture

$b_{\text {hyd }}[\mathrm{m}] \quad$ hydraulic aperture

$b_{\text {hyd.def }}[\mathrm{m}]$ hydraulic aperture of a deformed fracture

$b_{\text {ohyd }}[\mathrm{m}] \quad$ initial hydraulic aperture

$g\left[\mathrm{~m} / \mathrm{s}^{2}\right] \quad$ gravity

$h_{w}[\mathrm{~m}] \quad$ hydraulic head

$h_{W P T}[\mathrm{~m}] \quad$ hydraulic head, water pressure test

$d h[\mathrm{~m}] \quad$ difference in hydraulic head

$H[\mathrm{~m}] \quad$ tunnel depth

$I[\mathrm{~m}] \quad$ penetration length

$I_{d e f}[\mathrm{~m}]$ penetration length for a deformed fracture,

$I_{D}[-] \quad$ penetration length (dimensionless)

$I_{D-1 D}[-]$ penetration length (dimensionless), 1D-flow

$I_{D-2 D}[-] \quad$ penetration length (dimensionless), 2D-flow

$I_{G}[\mathrm{~m}] \quad$ parameter defining length-scale, scaling factor

$k_{n}[\mathrm{~Pa} / \mathrm{m}] \quad$ fracture normal stiffness

$p[\mathrm{~Pa}] \quad$ fluid pressure

$p_{g}[\mathrm{~Pa}] \quad$ grouting pressure

$p_{w}[\mathrm{~Pa}] \quad$ natural water pressure 
$p_{W P T}[\mathrm{~m}] \quad$ injection pressure, water pressure test

$\Delta p[\mathrm{~Pa}] \quad$ fluid pressure change, grouting overpressure

$Q\left[\mathrm{~m}^{3} / \mathrm{s}\right] \quad$ flow

$\mathrm{Q} / \mathrm{dh}\left[\mathrm{m}^{2} / \mathrm{s}\right]$ specific capacity

$r_{D}[-] \quad$ borehole radius divided by scaling factor, $I_{G}$

$r_{w}[\mathrm{~m}] \quad$ borehole radius

$t[\mathrm{~s}] \quad$ time

$t_{D}[-] \quad$ dimensionless time

$t_{G}[\mathrm{~s}] \quad$ gel induction time

$T\left[\mathrm{~m}^{2} / \mathrm{s}\right] \quad$ transmissivity

$\Delta u_{n}[\mathrm{~m}] \quad$ fracture normal deformation

$V\left[\mathrm{~m}^{3}\right] \quad$ volume, grout take

$V_{\text {field,t }}\left[\mathrm{m}^{3}\right]$ grout take measured in the field, at a certain time, $t$

$\Delta V\left[\mathrm{~m}^{3}\right] \quad$ fracture volume change

$\AA\left[\mathrm{Pa} \cdot \mathrm{m}^{2}\right] \quad$ areal integral of the fluid pressure change

$\alpha[-] \quad$ factor depending upon the rheology of the silica sol

$\mu_{w}[\mathrm{Pas}] \quad$ viscosity (water)

$\mu_{0}[\mathrm{Pas}] \quad$ viscosity (grout)

$\rho_{r}\left[\mathrm{~kg} / \mathrm{m}^{3}\right] \quad$ density of the rock

$\rho_{w}\left[\mathrm{~kg} / \mathrm{m}^{3}\right]$ density of water

$\sigma_{n}[\mathrm{~Pa}] \quad$ normal stress

$\sigma_{n}^{\prime}[\mathrm{Pa}] \quad$ effective normal stress

$\sigma_{z}[\mathrm{~Pa}] \quad$ vertical stress, stress due to the overburden 


\section{Tables}

Table 1 Estimate of initial hydraulic aperture, $b_{0}$.

\begin{tabular}{ccccccc}
\hline & $\begin{array}{c}r_{w} \\
{[\mathrm{~m}]}\end{array}$ & $\begin{array}{c}h_{w} \\
{[\mathrm{~m}]}\end{array}$ & $\begin{array}{c}h_{W P T} \\
{[\mathrm{~m}]}\end{array}$ & $\begin{array}{c}Q \\
{[\mathrm{~L} / \mathrm{min}]}\end{array}$ & $\begin{array}{c}Q / d h \\
{\left[\mathrm{~m}^{2} / \mathrm{s}\right]}\end{array}$ & $\begin{array}{c}b_{0} \\
{[\mu \mathrm{m}]}\end{array}$ \\
\hline Nygård tunnel & & & & & & \\
Fan 1 bh 18 & 0.032 & 50 & 150 & $\sim 0.4$ & $5.8 \mathrm{E}-08$ & 45 \\
Fan 1 bh 11 & 0.032 & 50 & 150 & 5.0 & $8.3 \mathrm{E}-07$ & 110 \\
Fan 5 bh 23 & 0.032 & 50 & 175 & 8.6 & $1.1 \mathrm{E}-06$ & 122 \\
Fan 5 bh 18 & 0.032 & 50 & 188 & 11.8 & $1.4 \mathrm{E}-06$ & 131 \\
Äspö HRL & & & & & & \\
5F03 & 0.038 & 50 & 72 & $\sim 0.8$ & $\sim 6.0 \mathrm{E}-7$ & 95 \\
Fan 1A bh 41 & 0.031 & 290 & 0 & 27.0 & $1.6 \mathrm{E}-06$ & 135 \\
\hline
\end{tabular}


Table 2 Estimate of fracture stiffness

\begin{tabular}{cccccccccc}
\hline & $\begin{array}{c}p_{g} \\
{[\mathrm{MPa}]}\end{array}$ & $\begin{array}{c}p_{w} \\
{[\mathrm{MPa}]}\end{array}$ & $\begin{array}{c}b_{\text {def }} \\
{[\mu \mathrm{m}]}\end{array}$ & $\begin{array}{c}b_{\text {def }}-b_{0} \\
{[\mu \mathrm{m}]}\end{array}$ & $\begin{array}{c}I \\
{[\mathrm{~m}]}\end{array}$ & $\begin{array}{c}I_{\text {def }} \\
{[\mathrm{m}]}\end{array}$ & $\begin{array}{c}I_{\text {def }} \\
I\end{array}$ & $\begin{array}{c}\AA_{\text {cone }} \\
{\left[\mathrm{Pam}{ }^{2}\right]}\end{array}$ & $\begin{array}{c}k_{n} \\
{[\mathrm{GPa} / \mathrm{m}]}\end{array}$ \\
\hline $\begin{array}{c}\text { Nygård } \\
\text { tunnel }\end{array}$ & & & & & & & & & \\
$\begin{array}{c}\text { Fan 1 } \\
\text { bh 18 }\end{array}$ & 2.5 & 0.5 & 116 & 71 & 1.4 & 3.6 & 2.6 & $1.3 \mathrm{E}+07$ & 5 \\
$\begin{array}{l}\text { Fan 1 } \\
\text { bh 11 }\end{array}$ & 2.5 & 0.5 & 185 & 75 & 3.1 & 5.2 & 1.7 & $3.0 \mathrm{E}+07$ & 5 \\
$\begin{array}{c}\text { Fan 5 } \\
\text { bh 23 }\end{array}$ & 2.5 & 0.5 & 234 & 112 & 3.3 & 6.4 & 1.9 & $3.0 \mathrm{E}+07$ & 2 \\
$\begin{array}{c}\text { Fan 5 } \\
\text { bh 18 }\end{array}$ & 2.5 & 0.5 & 243 & 112 & 3.6 & 6.6 & 1.8 & $2.6 \mathrm{E}+07$ & 2 \\
$\begin{array}{l}\text { Äspö } \\
\text { HRL }\end{array}$ & & & & & & & & & \\
5F03 & 0.9 & 0.7 & 95.1 & 0.1 & 0.97 & 0.97 & 1.0 & $1.8 \mathrm{E}+05$ & $\sim 600$ \\
$\begin{array}{c}\text { Fan 1A } \\
\text { bh 41 }\end{array}$ & 6.0 & 2.9 & 193 & 58 & 4.5 & 6.4 & 1.4 & $2.6 \mathrm{E}+08$ & 35 \\
\hline
\end{tabular}


Table 3 Results for the two tunnels.

\begin{tabular}{|c|c|c|}
\hline & Nygård tunnel (50 m depth): & $\begin{array}{l}\text { Äspö Hard Rock Laboratory } \\
\text { (450 m depth): }\end{array}$ \\
\hline Flow dimension & $\begin{array}{l}\text { Larger than or close to } 2 \mathrm{D} \text { (from } \\
\text { grouting field data) - indicating } \\
\text { deforming fractures. }\end{array}$ & $\begin{array}{l}\text { Larger than or close to } 2 \mathrm{D} \text { (from } \\
\text { grouting field data). The second } \\
\text { borehole possibly smaller than } \\
\text { 2D flow (channeled flow). }\end{array}$ \\
\hline Rock stresses & $\begin{array}{l}\text { Low rock stress due to the } \\
\text { weight of the overburden and } \\
\text { redistribution of stresses around } \\
\text { the tunnel. Tunnel at } 50 \mathrm{~m} \text { depth, } \\
\text { vertical stress: } \sigma_{z} \approx 1.3 \mathrm{MPa} \text {. }\end{array}$ & $\begin{array}{l}\text { High rock stress due to the } \\
\text { weight of the overburden ( } 450 \mathrm{~m} \\
\text { depth), vertical stress: } \sigma_{\mathrm{z}} \approx 12 \\
\text { MPa. Possibly lower close to the } \\
\text { tunnel due to redistribution of } \\
\text { stresses. }\end{array}$ \\
\hline $\begin{array}{l}\text { Fluid pressure } \\
\text { (estimated) }\end{array}$ & $p_{w}+\Delta p / 3 \approx 1.2 \mathrm{MPa}$ & $p_{w}+\Delta p / 3 \approx 3.9 \mathrm{MPa}$ or $0.8 \mathrm{MPa}$ \\
\hline Effective stress & $\begin{array}{l}\text { Likely to be low (small } \\
\text { difference between estimated } \\
\text { fluid pressure and vertical } \\
\text { stress). }\end{array}$ & $\begin{array}{l}\text { The resulting effective stress } \\
\text { could be low close to the tunnel. } \\
\text { Depends upon the fracture } \\
\text { orientation and location. }\end{array}$ \\
\hline $\begin{array}{l}\text { Estimated } \\
\text { fracture normal } \\
\text { stiffness }\end{array}$ & $\begin{array}{l}\text { Low estimated fracture stiffness } \\
(2-5 \mathrm{GPa} / \mathrm{m}) \text { using the } \\
\text { presented method - indicating } \\
\text { deforming fractures. }\end{array}$ & $\begin{array}{l}\text { High stiffness compared to } \\
\text { Nygård tunnel data ( } 35 \text { and } \\
\text { approx. } 600 \mathrm{GPa} / \mathrm{m} \text { ). Reasonable } \\
\text { considering the depth and the } \\
\text { likelihood of higher rock } \\
\text { stresses. }\end{array}$ \\
\hline
\end{tabular}




\section{Figures}

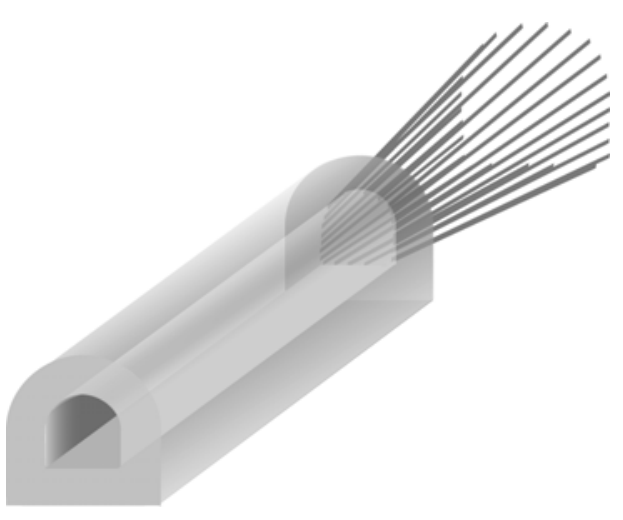

(a)

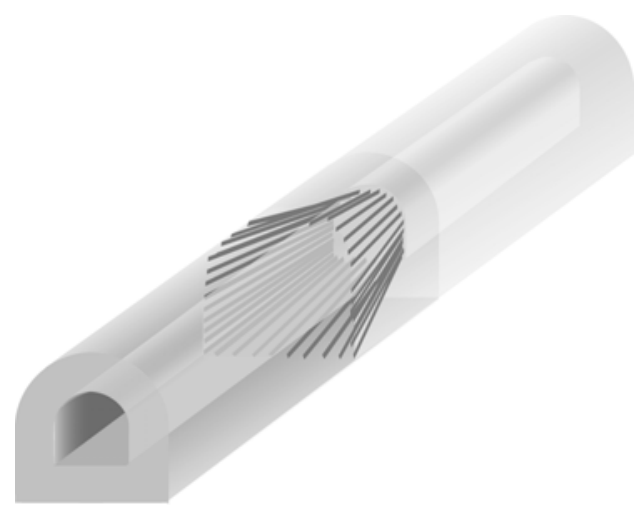

(b)

Fig. 1. (a) Pre-excavation grouting with grouting boreholes drilled in tunnel front. (b) Post-excavation grouting with boreholes drilled in the tunnel wall. During hydraulic testing and grouting fracture deformation may occur due to redistribution of stresses or the tunnel being found at shallow depth. 


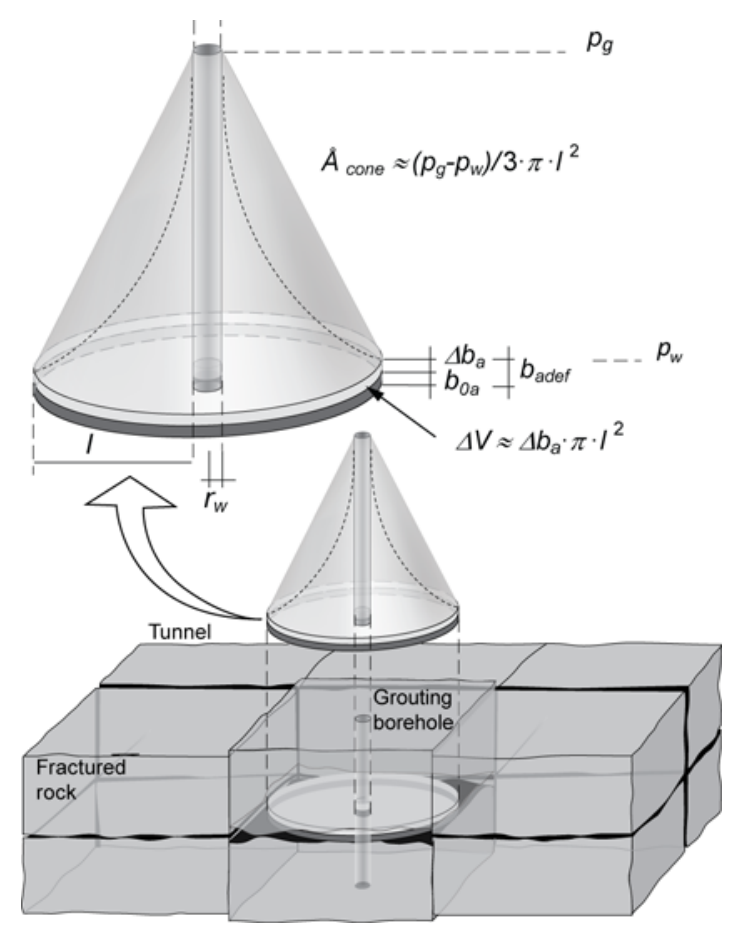

Fig. 2. Conceptual sketch of grout penetration and deformation. The change in fluid pressure due to grouting results in opening of a fracture. 


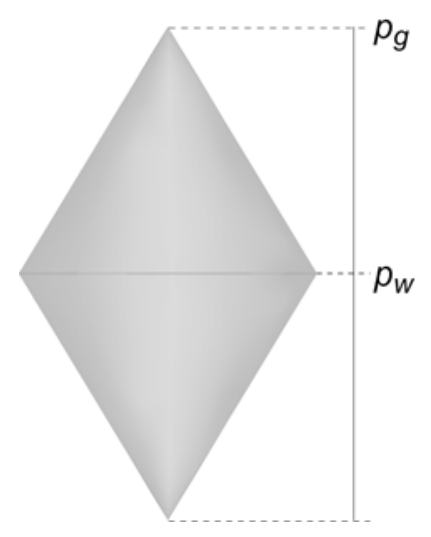

a)

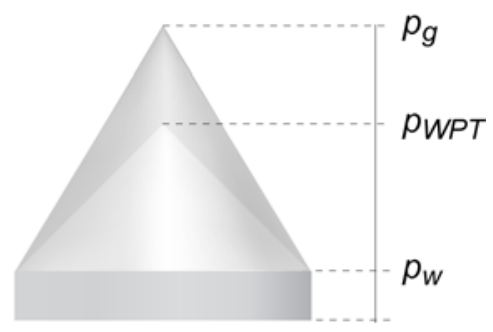

b)

Fig. 3. Areal integral of fluid pressure change. $p_{w}$ is natural pressure, $p_{W P T}$, pressure for water pressure test and $p_{g}$ grouting pressure. Initial aperture estimated by a) natural inflow measurements and b) water pressure tests. For a) areal integrals are summarized and for $b$ ) the difference is used. 


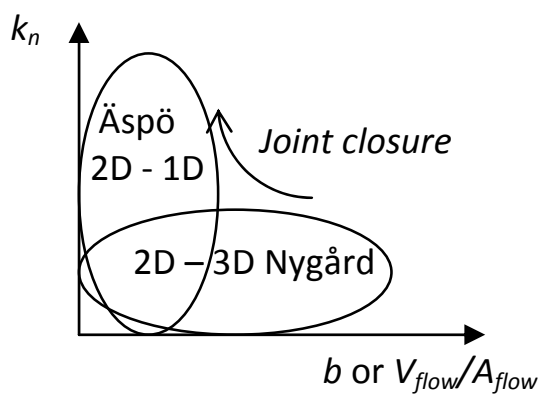

Nygård (shallow): 2D (3D) flow - few points of contact: $k_{n}$ low (small variation). High values of $V_{\text {flow }} / A_{\text {flow }}$ or aperture, $b$, (radial flow). Deformation due to low effective stress.

Äspö (deep): 2D (3D), see above. 2D to 1D flow - larger number of points of contact: $k_{n}$ high. Low values of $V_{\text {flow }} / A_{\text {flow }}$, (going towards channeled flow). Higher effective stress and no (small) deformation.

Fig. 4. Sketch coupling flow dimension, aperture, $b$, volume and area available to flow $\left(V_{\text {flow }}\right.$ and $\left.A_{\text {flow }}\right)$ and deformation (normal fracture stiffness, $\left.k_{n}\right)$. An open fracture with few points of contact and no fracture filling (2D flow) is more likely to deform ( $2 D$ to $3 D$ flow, few points of contact and low fracture normal stiffness) and therefore it is important to identify these features for grouting purposes. 